\title{
Aggregate binding agents improve soil aggregate stability in Robinia pseudoacacia forests along a climatic gradient on the Loess Plateau, China
}

\author{
JING Hang ${ }^{1}$, MENG Min ${ }^{1}$, WANG Guoliang ${ }^{1,2}$, LIU Guobin ${ }^{1,2^{*}}$ \\ ${ }^{1}$ State Key Laboratory of Soil Erosion and Dryland Farming on the Loess Plateau, Institute of Soil and Water Conservation, \\ Northwest A\&F University, Yangling 712100, China; \\ ${ }^{2}$ Institute of Soil and Water Conservation, Chinese Academy of Science and Ministry of Water Resources, Yangling 712100 , \\ China
}

\begin{abstract}
The distribution of binding agents (i.e., soil organic carbon (SOC) and glomalin-related soil protein (GRSP)) in soil aggregates was influenced by many factors, such as plant characteristics and soil properties. However, how these factors affect binding agents and soil aggregate stability along a climatic gradient remained unclear. We selected the Robinia pseudoacacia L. forests from semi-arid to semi-humid of the Loess Plateau, China to analyze the plant biomass, soil physical-chemical properties, SOC and GRSP distribution in different sized soil aggregates. We found that from semi-arid to semi-humid forests: (1) the proportion of macro-aggregates $(>0.250 \mathrm{~mm})$ significantly increased $(P<0.05)$, whereas those of micro-aggregates $(0.250-0.053 \mathrm{~mm})$ and fine materials $(<0.053 \mathrm{~mm})$ decreased and soil aggregate stability was increased; (2) the contents of SOC and GRSP in macro-aggregates and micro-aggregates significantly increased, and those in fine materials decreased; (3) the contribution of SOC to soil aggregate stability was greater than those of total GRSP and easily extractable GRSP; (4) soil properties had greater influence on binding agents than plant biomass; and (5) soil aggregate stability was enhanced by increasing the contents of SOC and GRSP in macro-aggregates and soil property was the important part during this process. Climate change from semi-arid to semi-humid forests is important factor for soil structure formation because of its positive effect on soil aggregates.
\end{abstract}

Keywords: binding agents; glomalin; organic carbon; soil property; soil aggregate stability

Citation: JING Hang, MENG Min, WANG Guoliang, LIU Guobin. 2021. Aggregate binding agents improve soil aggregate stability in Robinia pseudoacacia forests along a climatic gradient on the Loess Plateau, China. Journal of Arid Land, 13(2): 165-174. https://doi.org/10.1007/s40333-021-0002-8

\section{Introduction}

Most ecological processes (e.g., soil respiration, gas emission and nutrient accumulation) occur in soil structure composed of aggregates, and the soil stability depends on the type and content of binding agents. Climatic conditions usually change the binding agents by affecting various ecological factors, such as plant characteristics and soil properties, and alter soil aggregate stability (Zhang et al., 2012).

Studies have found that soil organic carbon (SOC) and glomalin-related soil protein (GRSP) are binding agents in soil aggregates. However, which one is more important in the formation of aggregates is currently controversial. Most studies believe that SOC has higher aggregation

*Corresponding author: LIU Guobin (E-mail: gbliu@ms.iswc.ac.cn)

Received 2020-03-27; revised 2020-08-31; accepted 2020-09-10

(C) Xinjiang Institute of Ecology and Geography, Chinese Academy of Sciences, Science Press and Springer-Verlag GmbH Germany, part of Springer Nature 2021 
efficiency than GRSP, because of its higher content (Six et al., 2002). For example, Xiao et al. (2020) found that soil aggregate stability was strongly related with SOC along a gradient of secondary succession, and SOC content was higher than GRSP. Studies found that SOC was very inefficient in the formation of aggregates, because SOC contains several inert components (Zhang et al., 2012; Singh et al., 2016). On the contrary, other researchers have revealed that GRSP, especially the easily extractable GRSP (EE-GRSP), is highly active, and the ability of glomalin-binding aggregates may be greater than that of SOC (Spohn and Giani, 2010). EE-GRSP in black soil of Northeast China is responsible for stabilizing soil aggregates instead of SOC (Zhang et al., 2012). Besides, a strong relationship between EE-GRSP and aggregate stability was found among different conservation tillage systems, which also supports the important role of EE-GRSP in the formation of aggregates. Recent studies have found that GRSP in different sized aggregates has varied contribution to aggregate stability (Zhang et al., 2014). For example, non-tillage management promotes the production of glomalin in macro- and micro-aggregates, thereby improving aggregate stability in a field experiment at Central China (Dai et al., 2015). Meanwhile, sustainable farming management including no till age, continuous crop coverage and light pruning increased the content of water stable aggregates by enhancing the accumulation of glomalin in macro-aggregates in an olive grove at southern Italy (Lombardo et al., 2019). Binding agents in macro-aggregates contributed more to soil structure than those in other sized aggregates, due to its higher content and sensitivity to environmental changes (Singh et al., 2016).

The content of GRSP and SOC in aggregates is directly influenced by soil properties and plant characteristics (Clair and Lynch, 2010; Wang et al., 2016; Wang et al., 2018; Yue et al., 2018). For example, soils with neutral or low $\mathrm{pH}$ improve root and fungal growth, and produce abundant glomalin and SOC (Wang et al., 2015; Zhong et al., 2017). Low content of soil nutrients, such as carbon $(\mathrm{C})$, nitrogen $(\mathrm{N})$, and phosphorus $(\mathrm{P})$ increases the lifespan of ectomycorrhizal roots and reduces the rate of GRSP decomposition (Lovelock et al., 2003, 2004). Increased plant biomass is beneficial to arbuscular mycorrhizal fungi (AMF) colonization and GRSP accumulation (Wang et al., 2018). Climatic conditions, such as precipitation and temperature, have profound effects on soil properties and plant characteristics, which may lead to changes in GRSP and SOC (Treseder and Allen, 2000). Therefore, climatic conditions change soil structure by affecting these factors, but the mechanisms remain unclear. On one hand, the increasing precipitation and temperature across semi-arid and semi-humid forest ecosystems improves soil quality, which, in turn accelerates the decomposition of organic matter (Clair and Lynch, 2010). On the other hand, plant biomass and primary productivity are higher in semi-humid forests than in semi-arid forests, which are conducive to AMF infection and glomalin production (Wang et al., 2016; Yue et al., 2018). The decomposition and production of binding agents are enhanced at the same time, and soil aggregate stability depends on the combined effects of these biochemical processes along a climatic gradient. Based on previous studies, this work will explore the variations of binding agents and soil aggregate stability caused by climate change. The effects of plant characteristics and soil properties during this process were evaluated.

In this study, Robinia pseudoacacia L. forests along a climatic gradient (from semi-arid to semi-humid) on the Loess Plateau, China, were selected as the research objects. We focused on the biomass of $R$. pseudoacacia, soil physical-chemical properties and distribution of EE-GRSP, total GRSP (T-GRSP) and SOC in soil aggregates. Using correlation analysis and combining with redundancy analysis (RDA), we analyzed the contribution of binding agents to soil aggregate stability and the effects of plant biomass and soil physical-chemical properties on the stability.

\section{Materials and methods}

\subsection{Study area}

R. pseudoacacia forests at Shenmu City (SM), Suide County (SD), Ansai District (AS) and Chunhua County $(\mathrm{CH})$ from the north to the south of the Loess Plateau, China were selected $\left(34^{\circ} 46^{\prime}-38^{\circ} 44^{\prime} \mathrm{N}, 108^{\circ} 31^{\prime}-110^{\circ} 29^{\prime} \mathrm{E} ; 1100-1200 \mathrm{~m}\right.$ a.s.1.). Sampling locations are presented in Figure 1. Annual average temperature of the four study sites was $9.2^{\circ} \mathrm{C}-10.6^{\circ} \mathrm{C}$, annual minimum temperature was $-24.0^{\circ} \mathrm{C}--29.0^{\circ} \mathrm{C}$ in January, and annual maximum temperature was 
$36.0^{\circ} \mathrm{C}-42.0^{\circ} \mathrm{C}$ in July. Average annual precipitation was $390.3-585.7 \mathrm{~mm}$. The study sites belonged to the transitional zone from semi-arid to semi-humid forest ecosystems and was dominated by continental monsoon climate, with distinct seasonal and micro-climates. The soil of $R$. pseudoacacia forests was mainly loessal soil with a slope of $25^{\circ}-30^{\circ}$. The canopy density of the forests was $0.5-0.7$ and the diameter at breast height $(\mathrm{DBH})$ was $10-20 \mathrm{~cm}$. The shrubs and herbs in the forests included Ziziphus jujuba, Rosa xanthina, Stipa bungeana, Carex lanceolata, Artemisia scoparia, Saussurea romuleifolia. Information of the four study sites is shown in Table 1.

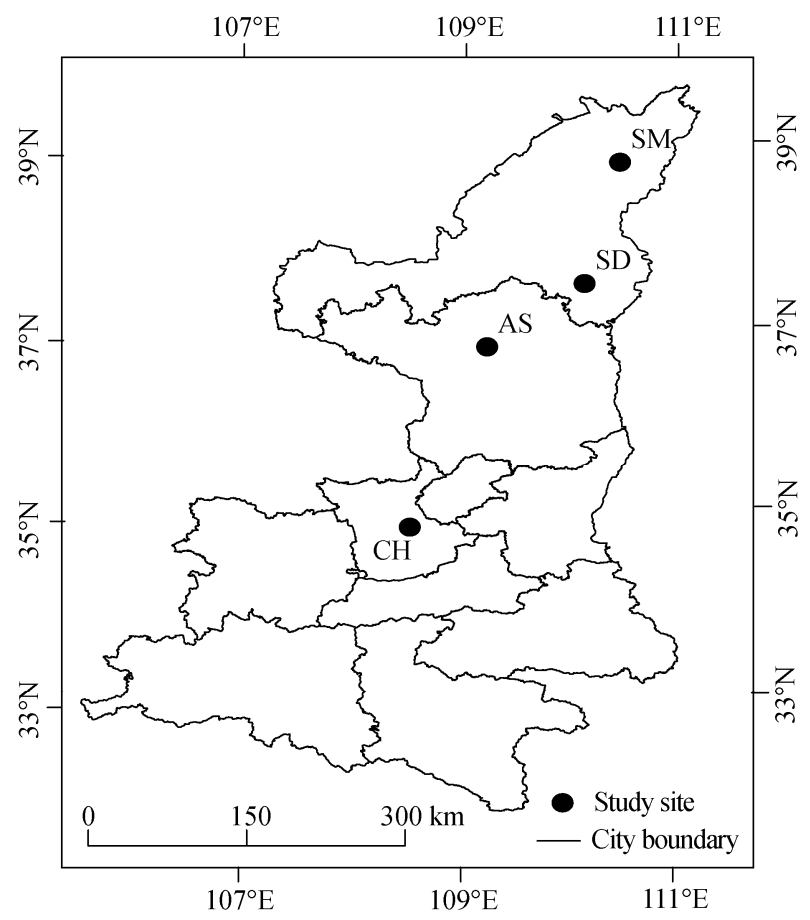

Fig. 1 Location of the study sites. SM, Shenmu City; SD, Suide County; AS, Ansai District; CH, Chunhua County.

Table 1 Information of the study sites

\begin{tabular}{|c|c|c|c|c|c|c|c|c|c|}
\hline Site & $\begin{array}{l}\text { Latitude and } \\
\text { longitude }\end{array}$ & $\begin{array}{l}\text { Altitude } \\
\text { (m) }\end{array}$ & $\begin{array}{l}\text { Precipitation } \\
(\mathrm{mm})\end{array}$ & $\begin{array}{c}\text { Temperature } \\
\left({ }^{\circ} \mathrm{C}\right)\end{array}$ & $\begin{array}{c}\text { Evaporation } \\
(\mathrm{mm})\end{array}$ & $\begin{array}{l}\text { Main } \\
\text { plants }\end{array}$ & $\begin{array}{l}\text { Tree } \\
\text { height } \\
(\mathrm{m})\end{array}$ & $\begin{array}{l}\mathrm{DBH} \\
(\mathrm{cm})\end{array}$ & $\begin{array}{l}\text { Soil } \\
\text { type }\end{array}$ \\
\hline SM & $\begin{array}{c}38^{\circ} 44^{\prime} 46^{\prime \prime} \mathrm{N} \\
110^{\circ} 29^{\prime} 48^{\prime \prime} \mathrm{E}\end{array}$ & 1204.4 & 390.3 & 9.2 & 1336.6 & $\begin{array}{l}\text { Locust, } \\
\text { yellow } \\
\text { rose }\end{array}$ & 6.91 & 18.18 & $\begin{array}{l}\text { Sand } \\
\text { loess }\end{array}$ \\
\hline $\mathrm{SD}$ & $\begin{array}{c}37^{\circ} 25^{\prime} 19^{\prime \prime} \mathrm{N} \\
110^{\circ} 09^{\prime} 55^{\prime \prime} \mathrm{E}\end{array}$ & 1178.3 & 410.5 & 10.1 & 2061.9 & $\begin{array}{c}\text { Locust, } \\
\text { Miscanthus }\end{array}$ & 7.44 & 16.33 & Loess \\
\hline AS & $\begin{array}{c}36^{\circ} 44^{\prime} 25^{\prime \prime} \mathrm{N} \\
109^{\circ} 15^{\prime} 11^{\prime \prime} \mathrm{E}\end{array}$ & 1110.9 & 506.5 & 9.2 & 1000.0 & $\begin{array}{c}\text { Locust, } \\
\text { Miscanthus }\end{array}$ & 12.35 & 17.35 & Loess \\
\hline $\mathrm{CH}$ & $\begin{array}{c}34^{\circ} 46^{\prime} 48^{\prime \prime} \mathrm{N} \\
108^{\circ} 31^{\prime} 44^{\prime \prime} \mathrm{E}\end{array}$ & 1276.5 & 585.7 & 10.6 & 520.0 & $\begin{array}{l}\text { Locust, } \\
\text { Jujube }\end{array}$ & 9.28 & 15.93 & Loess \\
\hline
\end{tabular}

Note: SM, Shenmu City; SD, Suide County; AS, Ansai District; CH, Chunhua County. DBH, diameter at breast height.

\subsection{Experimental design}

In September 2017, we selected plots $(20 \mathrm{~m} \times 10 \mathrm{~m}$ in each plot) with the same direction and slope on the basis of site conditions. Each site of $R$. pseudoacacia forests had five plots that were separated at least $20 \mathrm{~m}$ apart from each other. Species composition, height and DBH of $R$. pseudoacacia in each plot were recorded. Three undisturbed soil samples were randomly collected from $0-20 \mathrm{~cm}$ soil layer after litter was removed. The soil samples were frozen and carefully transported back to the laboratory. The three soil samples in each plot were mixed and gently broken apart. The roots and stones were removed simultaneously. One part of the soil 
sample was frozen for determining water content and AMF infection rate. Another part was used for determining soil physical-chemical properties, aggregate composition, SOC and GRSP contents after air drying.

\subsection{Soil aggregate distribution}

Soil aggregate distribution was determined using the wet sieving method (Six et al., 1998). Filter paper was spread on a glass dish and soaked with deionized water. Approximately $100 \mathrm{~g}$ soil sample was evenly spread on the filter paper for $30 \mathrm{~min}$. The soil sample was submerged on the water surface, and the impurities on the water surface were removed. Then, the subsample was shaken for $1 \mathrm{~min}$ on a wet sieve machine with a frequency of 50 times $/$ min and amplitude of $3 \mathrm{~cm}$. The subsample was separated into three classes for the different sized aggregates: $>0.250 \mathrm{~mm}$ (macro-aggregate), $0.250-0.053 \mathrm{~mm}$ (micro-aggregate) and $<0.053 \mathrm{~mm}$ (fine material). All separated soil and water were oven-dried at $45^{\circ} \mathrm{C}$, weighed and saved for laboratory analysis.

\subsection{GRSP extraction and determination}

GRSP content was determined in accordance with the method of Wrightand Upadhyaya (1998). Soil sample $(1 \mathrm{~g})$ and $8 \mathrm{~mL}$ of $50 \mathrm{mmol} / \mathrm{L}$ citrate solution $(\mathrm{pH}=7.0)$ were added to a $10-\mathrm{mL}$ centrifuge tube and autoclaved at $121^{\circ} \mathrm{C}$ for $60 \mathrm{~min}$. The sample was centrifuged at $10,000 \mathrm{r} / \mathrm{min}$ for $5 \mathrm{~min}$, and the supernatant was poured into a $50-\mathrm{mL}$ centrifuge tube. This procedure was repeated five times on the same soil sample to obtain the T-GRSP extract. The extract was mixed and stored for $3 \mathrm{~d}$ at $4{ }^{\circ} \mathrm{C}$. EE-GRSP extract was obtained in accordance with the above mentioned method, but the procedure was repeated once. T-GRSP and EE-GRSP contents of the extract were tested spectrophotometrically at $590 \mathrm{~nm}$ light via the Bradford dye-binding assay with bovine serum albumin as the standard.

\subsection{Soil property determination}

Dichromate oxidation (Mebius, 1960) and Kjeldahl methods (Page et al., 1982) were used to measure SOC and N contents, respectively. Soil P content was measured by persulfate oxidation followed by colorimetric analysis ( $\mathrm{Lu}, 2000)$. Soil $\mathrm{pH}$ was determined by potentiometry (Lu, 2000). The infection rate of AMF was observed via the trypan blue coloration method (Phillips and Hayman, 1970). Soil water content was determined by the drying method ( $\mathrm{Lu}, 2000)$.

\subsection{DBH and biomass determination of $\boldsymbol{R}$. pseudoacacia}

Above-ground biomass, root biomass and total biomass were determined using the allometric growth model of $R$. pseudoacacia forests on the Loess Plateau, China (Li, 2015). DBH was measured using a growth cone to extract the pith, and dichotomy was used to estimate the height of trees.

The allometric growth model was as follows:

$$
\ln (M)=a+b \ln (\mathrm{DBH})
$$

where $M$ is the biomass (kg); $a$ and $b$ are the estimates of model parameters that vary according to organ and diameter of trees, respectively; and DBH is the diameter at breast height $(\mathrm{cm})$.

\subsection{Statistical analyses}

Soil aggregate stability was evaluated by mean weight diameter (MWD) and geometric mean diameter (GMD). MWD and GMD were calculated using the following equations:

$$
\begin{gathered}
\mathrm{MWD}=\sum_{i=1}^{n} x_{i} w_{i}, \\
\mathrm{GMD}=\exp \left[\frac{\sum_{i=1}^{n} w_{i} \ln x_{i}}{\sum_{i=1}^{n} x_{i}}\right],
\end{gathered}
$$

where $x_{i}$ is the mean diameter of each sized aggregate $(\mathrm{mm}) ; w_{i}$ is the percentage of each sized aggregate (\%); and $n$ is the number of different sized aggregates.

One-way variance analysis was used to analyze the differences in soil physical-chemical 
property, aggregate distribution, stability, and SOC and GRSP contents among four sites $(P<0.05)$. Correlation analysis was used to compare the relationship between aggregate stability and binding agents. The above mentioned analysis was conducted using SPSS 20.0 statistical software package (SPSS Inc., Chicago, IL, USA). RDA was used to evaluate the effects of soil physical-chemical property and plant biomass on binding agents in soil aggregates. Analysis was conducted by CANOCO (v4.5, Microcomputer Power, Ithaca, NY, USA).

\section{Results}

\subsection{Soil property and $R$. pseudoacacia biomass}

$\mathrm{N}$, SOC and water contents were significantly increased, and $\mathrm{pH}$ was significantly decreased along the climatic gradient $(P<0.05$; Table 2$)$. $\mathrm{pH}$ at the $\mathrm{CH}$ site was almost neutral. AMF infection rate initially decreased and then increased along the climatic gradient. SM and $\mathrm{CH}$ sites had the highest value of infection. Above-ground biomass, root biomass and total biomass of $R$. pseudoacacia significantly increased along the climatic gradient and had the highest value at the $\mathrm{CH}$ site.

Table 2 Soil property and R. pseudoacacia biomass of the study sites

\begin{tabular}{|c|c|c|c|c|}
\hline \multirow{2}{*}{ Index } & \multicolumn{4}{|c|}{ Study site } \\
\hline & SM & $\mathrm{SD}$ & $\mathrm{AS}$ & $\mathrm{CH}$ \\
\hline $\mathrm{N}(\mathrm{mg} / \mathrm{g})$ & $0.31 \pm 0.059^{b}$ & $0.32 \pm 0.057^{b}$ & $0.33 \pm 0.033^{b}$ & $0.69 \pm 0.325^{\mathrm{a}}$ \\
\hline $\mathrm{P}(\mathrm{mg} / \mathrm{g})$ & $0.51 \pm 0.017^{\mathrm{b}}$ & $0.55 \pm 0.006^{\mathrm{ab}}$ & $0.57 \pm 0.030^{\mathrm{a}}$ & $0.56 \pm 0.050^{\mathrm{a}}$ \\
\hline $\mathrm{SOC}(\mathrm{mg} / \mathrm{g})$ & $4.73 \pm 0.759^{\mathrm{b}}$ & $3.01 \pm 0.349^{b}$ & $4.62 \pm 0.868^{\mathrm{b}}$ & $9.63 \pm 4.791^{\mathrm{a}}$ \\
\hline $\mathrm{pH}$ & $8.40 \pm 0.034^{\mathrm{b}}$ & $8.48 \pm 0.039^{\mathrm{a}}$ & $8.41 \pm 0.048^{\mathrm{b}}$ & $8.21 \pm 0.052^{c}$ \\
\hline Water content $(\%)$ & $6.36 \pm 0.736^{c}$ & $10.20 \pm 1.319^{\mathrm{b}}$ & $10.75 \pm 1.114^{\mathrm{b}}$ & $16.53 \pm 1.949^{\mathrm{a}}$ \\
\hline AMF infection rate $(\%)$ & $83.94 \pm 4.698^{\mathrm{a}}$ & $35.61 \pm 4.525^{\mathrm{b}}$ & $42.63 \pm 12.401^{\mathrm{b}}$ & $77.40 \pm 4.565^{\mathrm{a}}$ \\
\hline Above-ground biomass (kg) & $76.84 \pm 5.396^{\mathrm{b}}$ & $60.11 \pm 20.442^{\mathrm{b}}$ & $102.73 \pm 21.453^{\mathrm{a}}$ & $111.63 \pm 23.854^{\mathrm{a}}$ \\
\hline Root biomass (kg) & $39.03 \pm 2.488^{\mathrm{b}}$ & $31.11 \pm 9.675^{\mathrm{b}}$ & $63.76 \pm 11.670^{\mathrm{a}}$ & $52.95 \pm 9.772^{\mathrm{a}}$ \\
\hline Total biomass $(\mathrm{kg})$ & $115.87 \pm 7.884^{\mathrm{b}}$ & $91.22 \pm 30.116^{\mathrm{b}}$ & $166.49 \pm 33.122^{\mathrm{a}}$ & $164.58 \pm 33.626^{\circ}$ \\
\hline
\end{tabular}

Note: SM, Shenmu City; SD, Suide County; AS, Ansai District; CH, Chunhua County; N, nitrogen; P, phosphorus; SOC, soil organic carbon; AMF, arbuscular mycorrhizal fungi. Different lowercase letters within the same row indicate significant differences among the four study sites at $P<0.05$ level. Mean \pm SD.

\subsection{Distribution and stability of soil aggregates}

The proportions of macro-aggregates, micro-aggregates and fine materials were in the range of $19.43 \%-70.44 \%, 16.12 \%-47.61 \%$ and $4.34 \%-30.44 \%$, respectively. Soil at the $\mathrm{CH}$ site was dominated by macro-aggregates, whereas soils at the SM, SD and AS sites were primarily micro-aggregates (Fig. 2). From semi-arid to semi-humid forests, the proportion of macro-aggregates significantly increased, whereas those of micro-aggregates and fine materials significantly decreased $(P<0.05)$. MWD and GMD were significantly enhanced along the climatic gradient $(P<0.05)$.

\subsection{Distribution of SOC and GRSP in soil aggregates}

From semi-arid to semi-humid forests, the contents of T-GRSP and SOC in macro- and micro-aggregates significantly increased and had the highest values at the $\mathrm{CH}$ site $(P<0.05$; Fig. $3)$; the contents of T-GRSP and SOC in fine materials significantly decreased and had the highest value at the SM site; the content of EE-GRSP in macro- and micro-aggregates initially decreased and then increased with the highest values at the SM and $\mathrm{CH}$ sites, whereas the content of EE-GRSP in fine materials significantly decreased. Across all sized aggregates, the content of GRSP in macro-aggregates had the highest value, followed by that in micro-aggregates and fine materials. The distribution of SOC in aggregates was consistent with that in GRSP, except for that at the SM site. 


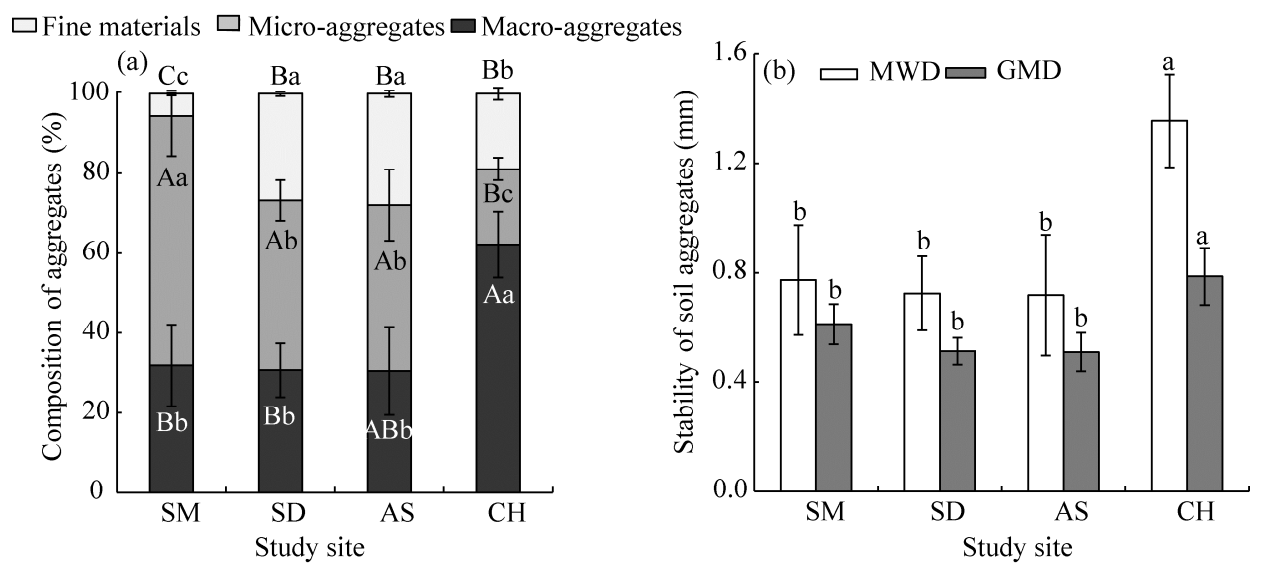

Fig. 2 Distribution (a) and stability (b) of soil aggregates at the study sites. Different lowercase letters indicate the significant differences among the study sites for each parameter at $P<0.05$ level. Different uppercase letters indicate significant difference among different sized aggregates at $P<0.05$ level. SM, Shenmu City; SD, Suide County; AS, Ansai District; CH, Chunhua County; MWD, mean weight diameter; GMD, geometric mean diameter; macro-aggregates, $>0.250 \mathrm{~mm}$; micro-aggregates, $0.250-0.053 \mathrm{~mm}$; fine materials, $<0.053 \mathrm{~mm}$.

$\square$ Fine materials $\square$ Micro-aggregates $\square$ Macro-aggregates
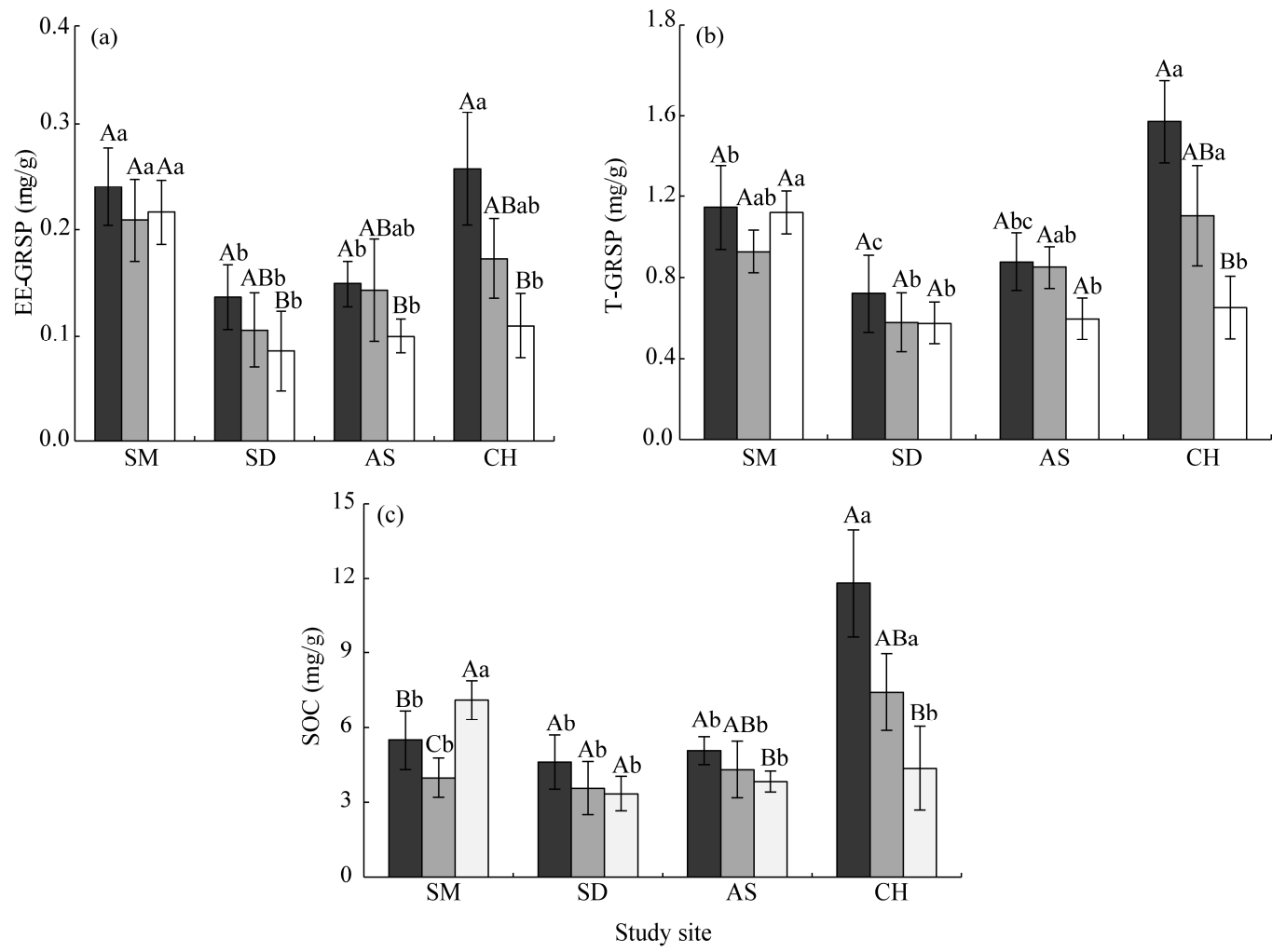

Fig. 3 Distribution of easily extractable glomalin-related soil protein (EE-GRSP, a), total extractable glomalin-related soil protein (T-GRSP, b) and soil organic carbon (SOC, c) in aggregates. Different lowercase letters indicate significant differences among the study sites for each parameter at $P<0.05$ level. Different uppercase letters indicate significant differences among different sized aggregates at $P<0.05$ level. SM, Shenmu City; SD, Suide County; AS, Ansai District; CH, Chunhua County; macro-aggregates, $>0.250 \mathrm{~mm}$; micro-aggregates, $0.250-0.053 \mathrm{~mm}$; fine materials, $<0.053 \mathrm{~mm}$.

\subsection{Correlation between soil aggregate stability and binding agents}

GRSP and SOC in macro-aggregates and micro-aggregates were significantly related with MWD 
$(P<0.05$, Table 3$)$, whereas no significant relationship was observed between MWD and binding agents in fine materials $(P>0.05)$. The correlation coefficient between SOC and MWD was greater than that between T-GRSP and MWD and that between EE-GRSP and MWD. The correlation coefficient between MWD and binding agents in macro-aggregates was greater than that in micro-aggregates.

Table 3 Bivariate correlation between mean weight diameter (MWD) and binding agents in soil aggregates

\begin{tabular}{ccccc}
\hline Index & Bulk soil & Macro-aggregates & Micro-aggregates & Fine materials \\
\hline EE-GRSP & ND & $0.574^{* *}$ & 0.339 & -0.001 \\
T-GRSP & ND & $0.711^{* *}$ & $0.587^{* *}$ & 0.110 \\
SOC & $0.750^{* *}$ & $0.795^{* *}$ & $0.758^{* *}$ & 0.115
\end{tabular}

Note: EE-GRSP and T-GRSP are easily extractable and total glomalin-related soil proteins, respectively; SOC, soil organic carbon; macro-aggregates, $>0.250 \mathrm{~mm}$; micro-aggregates, $0.250-0.053 \mathrm{~mm}$; fine materials, $<0.053 \mathrm{~mm}$; ND, not determined. ${ }^{*}$ and ${ }^{* *}$ indicate significances at $P<0.05$ and $P<0.01$ levels, respectively.

\subsection{RDA of ecological factors and binding agents}

The first and second axes accounted for $96.65 \%$ of the total variance in the data set (Fig. 4). The effect of soil property on binding agents was greater than that of $R$. pseudoacacia biomass. AMF infection rate had a strong effect on T-GRSP in macro-aggregates. SOC in macro-aggregates was affected by $\mathrm{N}$, water content and total biomass. $\mathrm{pH}$ had negative effects on T-GRSP and SOC in macro-aggregates.

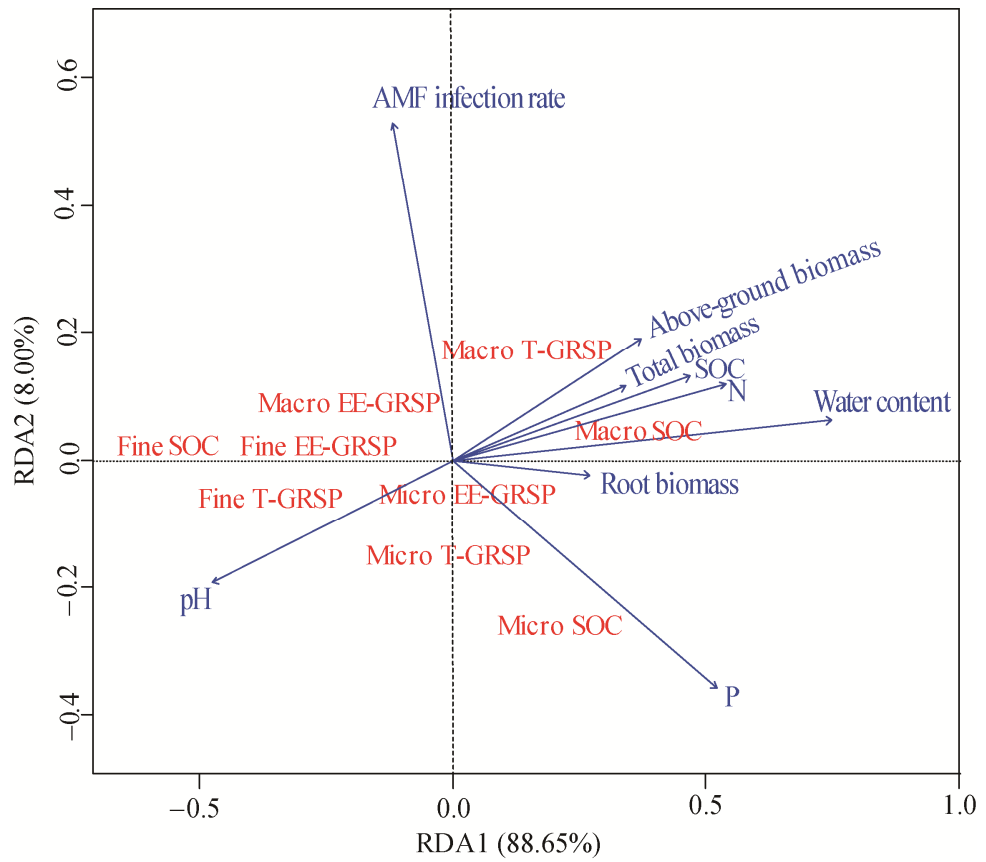

Fig. 4 Redundancy analysis (RDA) of binding agents, soil property and R. pseudoacacia growth index. N, nitrogen; P, phosphorus; SOC, soil organic carbon; AMF, arbuscular mycorrhizal fungi; EE-GRSP and T-GRSP are easily extractable and total glomalin-related soil proteins, respectively; macro-aggregates, $>0.250 \mathrm{~mm}$; micro-aggregates, $0.250-0.053 \mathrm{~mm}$; fine materials, $<0.053 \mathrm{~mm}$.

\section{Discussion}

\subsection{Composition and stability of soil aggregates along the climatic gradient}

Soil macro-aggregate proportion increased from semi-arid to semi-humid $R$. pseudoacacia forests on the Loess Plateau, China. This result was due to the increased content of binding agents and suitable precipitation and temperature conditions. Previous studies have confirmed that climatic 
condition promoted the large aggregate formation and binding agent production while decreasing the micro-aggregate proportion (Zhang et al., 2014; Xie et al., 2015; Luna et al., 2016). Different sized aggregates had varied changes because the increased soil quality caused by climate improvement converted small sized aggregates into large sized aggregates, thereby decreasing the proportion of micro-aggregates. Dai et al. (2015) also found that the proportion of 2-50 $\mu \mathrm{m}$ aggregates and binding agents had different responses to experimental treatments. In this study, soil aggregate stability was enhanced from semi-arid to semi-humid forests, which was related to the various effects of binding agents on soil aggregates.

\subsection{Distribution of binding agents in soil aggregates}

Improvement of climatic conditions (such as increasing precipitation and temperature) enhanced GRSP production and promoted the conversion of GRSP from fine materials to micro-aggregates and macro-aggregates. This phenomenon was consistent with the aggregate formation model, which was proposed by Six et al. (2004). That is, large sized aggregates were formed by the combination of small sized aggregates and binding agents. These results indicated that the size of aggregates should be considered when climatic conditions affected GRSP in forest ecosystems on the Loess Plateau, China. Different from farmland, GRSP in all sized aggregates of $R$. pseudoacacia forests had a similar response along the climatic gradient, which might be related to the infertile soil, limited precipitation and low temperature (Zhang et al., 2014). In addition, our results showed that the content of GRSP at the SM site (semi-arid) was significantly higher than those at the SD and AS sites. First, this phenomenon was attributed to the relatively poor soil at the SM site, which was conducive to the AMF growth, prolonging the lifespan and decreasing the decomposition rate of organic matter (Lovelock et al., 2003; Lovelock et al., 2004). Second, precipitation and soil water content are low at the SM site, therefore binding agents, such as GRSP, could not further combine with soil particles to form aggregates, resulting in no improvement in aggregate stability. As shown in Figure 2, MWD and macro-aggregate proportions at the SM site were significantly lower than those at other sites. These results indicate that aggregate formation by glomalin requires suitable hydrothermal conditions on the semi-arid/semi-humid forests.

SOC and GRSP in aggregates had different responses along the climatic gradient. Low annual precipitation and temperature resulted in poor soil quality and less production of SOC, whereas climatic condition at the SM site was favored for GRSP accumulation. Meanwhile, GRSP had lesser contribution to SOC compared with other components (Zhu et al., 2019). A study in Northeast China had found that SOC was primarily composed of inert carbon during urbanization, and glomalin did not contribute to the accumulation of inert carbon (Wang et al., 2018). In this study, SOC in aggregates was primarily affected by climatic conditions, whereas GRSP was affected by climate conditions and AMF characteristics.

\subsection{Relationship between binding agents and aggregate stability}

Binding agents in macro-aggregate had more contribution to aggregate stability than those in micro-aggregate and fine materials. From semi-arid to semi-humid forests, climatic conditions were favored for combination of macro-aggregate and improving soil structure (Zhang et al., 2014).

The contribution of SOC to aggregate stability was greater than those of T-GRSP and EE-GRSP, which was not in line with our assumption. The effect of binding agents on aggregate stability depended on two aspects: aggregation efficiency and content of binding agents. These two aspects determined the relationship between binding agents and soil stability (Rillig et al., 2001; Six et al., 2002; Rillig, 2004). EE-GRSP had a high binding efficiency, but considerably low content, which resulted in negligible influence on aggregate stability. Zhu et al. (2019) did not find a significant relationship between EE-GRSP and aggregate stability in southwestern China. SOC contained various inert components with a low binding ability, but its content was higher than that of EE-GRSP (SOC content in this study was 33.8 times higher than that of EE-GRSP). Therefore, SOC had a greater influence on aggregate stability than EE-GRSP. 


\subsection{RDA of ecological factors and binding agents}

From semi-arid to semi-humid forests on the Loess Plateau, climatic conditions promoted the growth of $R$. pseudoacacia and soil quality (Clair and Lynch, 2010; Wang et al., 2016; Yue et al., 2018). AMF infection rate was high at the SM site (semi-arid) because soil with low nutrients was conducive to fungal growth and prolonged mycorrhizal lifespan (Treseder and Allen, 2000).

RDA showed that the effect of soil property on binding agent was greater than that of plant biomass. This result was consistent with the research in a farmland (Sarker et al., 2018). Although plant biomass of $R$. pseudoacacia forests was evidently superior to that of farmland, soil property was still the most important factor affecting binding agent in soil aggregates. Soil $\mathrm{N}$ was the important index that increased plant growth and microbial activity, leading to a strong effect on the distribution of SOC in aggregates (Aber et al., 1998; Hong et al., 2017). Value of pH determined the rate of decomposition of litter and activity of AMF. Neutral soil was beneficial to the accumulation of different binding agents (Wang et al., 2018). Infection rate directly controlled AMF colonization and GRSP production. Soil water content was a limiting factor for microbial community in the sites of semi-humid and semi-arid forests, resulting in a remarkable effect on the accumulation of $\mathrm{OC}$ in aggregates. Soil $\mathrm{N}, \mathrm{pH}, \mathrm{AMF}$ infection rate and water content had positive effects on accumulation of binding agents. The abovementioned results were supported by previous studies. For example, Wang et al. (2014) showed that soil $\mathrm{pH}$ was the primary factor that changed glomalin between soil layers. C, N and water content were important for GRSP accumulation in different soil types of farmlands (Zhong et al., 2017). From semi-arid to semi-humid forests, our study emphasized the role of soil property in improving stability of soil structure.

\section{Conclusions}

Plant primary production, soil chemistry and structure in $R$. pseudoacacia forests gradually changed along the climatic gradient on the Loess Plateau, China. This study tested the mechanism of soil structure changing from semi-arid to semi-humid. First, SOC was a more efficient binding agent than that previously suggested. Second, soil chemistry had greater contribution to soil structure than vegetation factor. Third, some indices, such as $\mathrm{N}$ and AMF infection rate were emphasized during aggregate formation, providing reference for future research. These results revealed a potential way through which environmental conditions affected aggregate stability and multiple parts therein were elucidated.

\section{Acknowledgements}

This research was funded by the National Key Research and Development Program of China (2017YFC0504601) and the National Natural Science Foundation of China (41671513).

\section{References}

Aber J, McDowell W, Nadelhoffer K, et al. 1998. Nitrogen saturation in temperate forest ecosystems: Hypotheses revisited. BioScience, 48(11): 921-934.

Clair S B S, Lynch J P. 2010. The opening of pandora's box: climate change impacts on soil fertility and crop nutrition in developing countries. Plant and Soil, 335: 101-115.

Dai J, Hu J L, Zhu A N, et al. 2015. No tillage enhances arbuscular mycorrhizal fungal population, glomalin-related soil protein content, and organic carbon accumulation in soil macroaggregates. Journal of Soils and Sediments, 15: 1055-1062.

Hong M G, Nam B E, Kim J G. 2017. Effects of soil fertility on early development of wetland vegetation from soil seed bank: Focusing on biomass production and plant species diversity. Journal of Plant Biology, 60: 241-248.

Li T. 2015. Characteristics of carbon sequestration and effect factors of black locust plantations on the Loss Plateau of Shaanxi Province. Northwest Agriculture \& Forestry University, 11. (in Chinese)

Lombardo L, Palese A M, Grasso F, et al. 2019. Mechanical tillage diversely affects glomalin content, water stable aggregates and fungal community in the soil profiles of two differently managed olive orchards. Biomolecules, 9: 639 .

Lovelock C E, Andersen K, Morton J B. 2003. Arbuscular mycorrhizal communities in tropical forests are affected by host tree species and environment. Oecologia, 135(2): 268-279. 
Lovelock C E, Wright S F, Clark D A, et al. 2004. Soil stocks of glomalin produced by arbuscular mycorrhizal fungi across a tropical rain forest landscape. Journal of Ecology, 92(2): 278-287.

Lu R K. 2000. Methods for Soil Agrochemistry Analysis. Beijing: Agricultural Science and Technology Press, 106-310. (in Chinese)

Luna L, Miralles I, Andrenelli M C, et al. 2016. Restoration techniques affect soil organic carbon, glomalin and aggregate stability in degraded soils of a semiarid Mediterranean region. CATENA, 143: 256-264.

Mebius L J. 1960. A rapid method for the determination of organic carbon in soil. Analytica Chimica Acta, 22: 120-124.

Page A L, Miller R H, Keeney D R. 1982. Methods of soil analysis. CATENA, 15: 99-100.

Phillips J M, Hayman D S. 1970. Improved procedures for clearing roots and staining parasitic and vesicular-arbuscular mycorrhizal fungi for rapid assessment of infection. Transactions of the British Mycological Society, 55(1): 158-161.

Rillig M C, Wright S F, Nichols K A, et al. 2001. Large contribution of arbuscular mycorrhizal fungi to soil carbon pools in tropical forest soils. Plant and Soil, 233: 167-177.

Rillig M C. 2004. Arbuscular mycorrhizae, glomalin, and soil aggregation. Canadian Journal of Soil Science, 84(4): 355-363.

Sarker J R, Singh B P, Cowie A L, et al. 2018. Carbon and nutrient mineralisation dynamics in aggregate-size classes from different tillage systems after input of canola and wheat residues. Soil Biology and Biochemistry, 116: 22-38.

Singh A K, Rai A, Singh N. 2016. Effect of long term land use systems on fractions of glomalin and soil organic carbon in the Indo-Gangetic plain. Geoderma, 277: 41-50.

Six J, Elliott E T, Paustian K, et al. 1998. Aggregation and soil organic matter accumulation in cultivated and native grassland soils. Soil Science Society of America Journal, 62(5): 1367-1377.

Six J, Feller C, Denef K, et al. 2002. Soil organic matter, biota and aggregation in temperate and tropical soils-Effects of no-tillage. Agronomie, 22(7): 755-775.

Six J, Bossuyt H, Degryze S, et al. 2004. A history of research on the link between (micro) aggregates, soil biota, and soil organic matter dynamics. Soil and Tillage Research, 79: 7-31.

Spohn M, Giani L. 2010. Water-stable aggregates, glomalin-related soil protein, and carbohydrates in a chronosequence of sandy hydromorphic soils. Soil Biology and Biochemistry, 42(9): 1505-1511.

Treseder K K, Allen M F. 2000. Mycorrhizal fungi have a potential role in soil carbon storage under elevated $\mathrm{CO}_{2}$ and nitrogen deposition. New Phytologist, 147(1): 189-200.

Wang Q, Wu Y, Wang W J, et al. 2014. Spatial variations in concentration, compositions of glomalin related soil protein in poplar plantations in northeastern China, and possible relations with soil physicochemical properties. The Scientific World Journal, 160403.

Wang Q, Wang W J, He X Y, et al. 2015. Role and variation of the amount and composition of glomalin in soil properties in farmland and adjacent plantations with reference to a primary forest in northeastern China. PLoS ONE, 10: e0139623.

Wang W J, Wang Q, Zhou W, et al. 2018. Glomalin changes in urban-rural gradients and their possible associations with forest characteristics and soil properties in Harbin City, Northeastern China. Journal of Environmental Management, 224: $225-234$.

Wang W Y, Ouyang W, Hao F H, et al. 2016. Spatial impacts of climate factors on regional agricultural and forestry biomass resources in north-eastern province of China. Frontiers of Environmental Science and Engineering, 10: 174.

Wright S F, Upadhyaya A. 1998. A survey of soils for aggregate stability and glomalin, a glycoprotein produced by hyphae of arbuscular mycorrhizal fungi. Plant and Soil, 198: 97-107.

Xiao L, Yao K H, Li P, et al. 2020. Increased soil aggregate stability is strongly correlated with root and soil properties along a gradient of secondary succession on the Loess Plateau. Ecological Engineering, 143: 105671.

Xie H T, Li J W, Zhang B, et al. 2015. Long-term manure amendments reduced soil aggregate stability via redistribution of the glomalin-related soil protein in macroaggregates. Scientific Reports, 5: 14687.

Yue J W, Guan J H, Yan M J, et al. 2018. Biomass carbon density in natural oak forests with different climate conditions and stand ages in northwest China. Journal of Forest Research, 23(6): 354-362.

Zhang S X, Li Q, Zhang X P, et al. 2012. Effects of conservation tillage on soil aggregation and aggregate binding agents in black soil of Northeast China. Soil and Tillage Research, 124: 196-202.

Zhang X K, Wu X, Zhang S X, et al. 2014. Organic amendment effects on aggregate-associated organic C, microbial biomass C and glomalin in agricultural soils. CATENA, 123: 188-194.

Zhong Z L, Wang W J, Wang Q, et al. 2017. Glomalin amount and compositional variation, and their associations with soil properties in farmland, northeastern China. Journal of Plant Nutrition and Soil Science, 180(5): 563-575.

Zhu R H, Zheng Z C, Li T X, et al. 2019. Effect of tea plantation age on the distribution of glomalin-related soil protein in soil water-stable aggregates in southwestern China. Environmental Science and Pollution Research, 26: 1973-1982. 